\title{
Power Quality Analysis and Evaluation of High-Speed Railway Traction Power Supply System
}

\author{
Hang Liu *, Qunzhan Li \\ School of Electrical Engineering, Southwest Jiaotong University, Chengdu, China \\ Email: john.liuhang@gmail.com
}

Keywords: high-speed railway; traction power supply system; power quality; voltage unbalance; harmonics

\begin{abstract}
With the rapidly developing of electrified railways; the power quality problems caused by traction power supply system have been increasing taken into account by railway and electricity department. In order to evaluate power quality, the models based on PSCAD/EMTDC of typical traction power supply system and traction loads have been established. The voltage unbalance, harmonics and flicker under worst case of traction loads have been detailed analysis by the model based on PSCAD/EMTDC. The result of simulation analysis is credible and valuable in practical project.
\end{abstract}

\section{Introduction}

In recent years, china's railway construction has entered a stage of rapid development. With the rapid development of high-speed railway, power quality problem has become an important issue of traction power supply system. Power quality problems are mainly caused by traction load. Most of traction load of high-speed electrified railway are CRH series EMUs and the HX series AC locomotives. Power quality problems in high-speed railway traction power supply system mainly are voltage unbalance, harmonics problems. So, the negative sequence, harmonic power quality problems should be analyzed and evaluated. It is important for the development of traction power supply system. [1-3]

Many scholars have studied the traction power supply system power quality problems. The author has studied the traction load forecasting and estimation, those studies as a basis for power quality in this paper. ${ }^{[4]}$

In this paper, a new method of power quality analysis and evaluation for traction power supply system is presented. Based on PSCAD / EMTDC simulation platform, traction power supply system and traction load model is constructed. And negative, harmonic power quality impact of traction power supply system is simulated and analyzed. The simulation results were compared with the IEC standards, which show that the method is correct and effective.

\section{Power Quality of Traction Power System}

AC traction power system provides power for traction loads. On some systems a small amount of auxiliary load is also supplied direct from the catenary system. It is normal to supply the loads radially from a series of substations placed along a railway route. 


\section{A. Voltage Unbalance}

Voltage asymmetry $(\mathrm{k})$ of a three phase system is defined as a relation of positive and negative sequence components according to IEC 61000-2-12:

$$
\mathrm{k}=\frac{\mathbb{v}_{2}}{\mathbb{W}_{1}}
$$

Where: $\mathrm{U}_{1}$ positive sequence component of voltage

$\mathrm{U}_{2}$ negative sequence component of voltage

\section{B. Harmonics}

At the point of common coupling (PCC) to the high voltage network the requirements of the supply authorities concerning harmonic currents and harmonic voltage distortion should to be considered. In order to assess the harmonic distortion, a calculation which considers the peak timetable has been carried out. The assessment of voltage harmonics is in accordance with IEC 61000-3-6. The calculations are based on the results of the network calculation with simulated train operation and the harmonic currents of the EMU. Following harmonic currents for an EMU with full traction load have been considered.

\section{1) Harmonic Currents:}

The harmonic currents will be fed into the catenary system by each train and will be transferred into the high voltage grid via the substation transformer. Trains feed harmonic currents at different points with different phase angles and magnitudes into the catenary system. The phase angle of the harmonic currents differs for each train.

\section{2) Harmonic Voltage Distortion :}

It is needed to calculate the distortions of harmonic current and voltage on PCC which conform or not to the harmonic standards, when the traction power supply system connected to the grid. Harmonic voltage distortion is an important indicator of quality evaluation for traction power supply system.

\section{3) Total harmoic voltage distortion}

The total harmonic voltage distortion factor can be calculated according to IEC 61000-3-6:

$$
\mathrm{THVD}=\sqrt{\sum_{\mathrm{v}=2}^{\mathrm{N}}\left(\frac{\mathrm{U}_{\mathrm{vx}}}{\mathrm{U}_{1}}\right)^{2}}
$$

With:

THVD total harmonic voltage distortion

$\mathrm{U}_{\mathrm{vx}} \quad$ voltage magnitude of harmonic order $\mathrm{v}$ for $\mathrm{x}$ trains 
v harmonic order

$\mathrm{N}$ number of harmonic order

Due to the calculation procedure the THVD is mainly determined by the maximum harmonics. Minor harmonics are negligible. [5-7]

\section{Simulation Results of Power Quality}

A model of traction power supply system is made by PSCAD/EMTDC, which is used to analyze quality problems. The traction system contains two traction power supply substations (TPSS1 and TPSS2) and four feeding sections as shown in Figure 1.

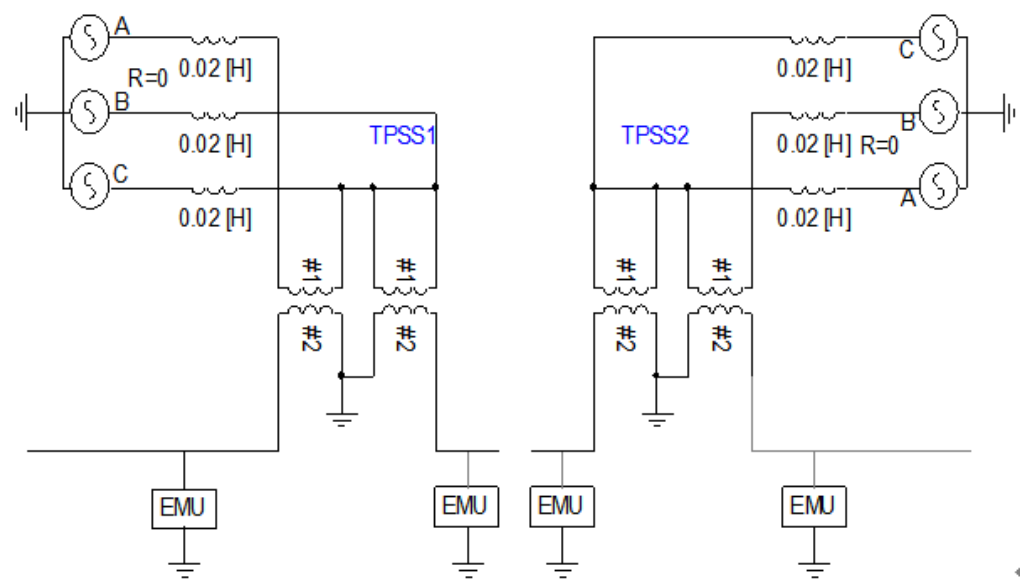

Figure 1: Model of traction power system

The traction transformer is $\mathrm{V}$-wiring. The capacity of transformer is 50MVA. The primary voltage of transformer is $220 \mathrm{kV}$, and the secondary side voltage is $27.5 \mathrm{kV}$.

Assuming the train operation a maximum number of thirteen EMUs are running during the three minutes headway, in both directions within the feeding section of TPSS1. With the same conditions a maximum number of fifteen EMUs are running on TPSS2. And the train operation a maximum number of eleven EMUs are running during the five minutes headway, in both directions within the feeding section of TPS1. With the same conditions a maximum number of thirteen EMUs are running on TPS2.

The maximum traction current of single EMU is 400A. Following harmonic currents for an EMU with full load have been considered. Following figure 2 shows 2-19 order maximum harmonic current of one EMU.

The traction power supply system is modeled and simulated on PSCAD / EMTDC simulation platform. The system voltage unbalance, harmonic power quality problems are analyzed. 


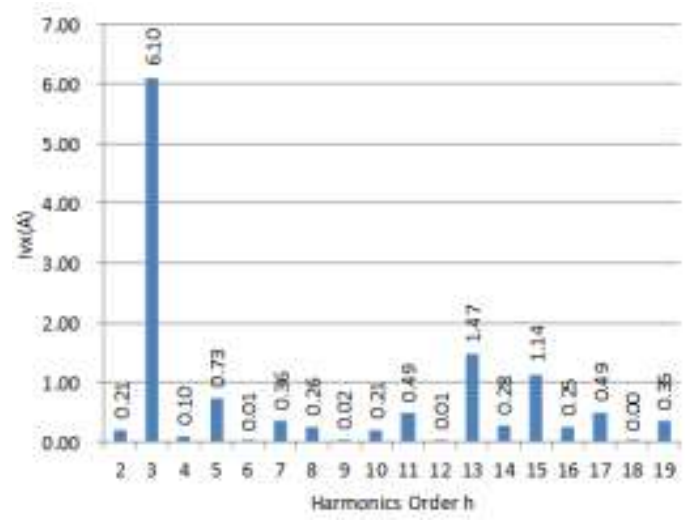

Figure 2: Maximum harmonic current of one EMU

\section{Voltage Unbalance Results}

Depending on the considered minimum system fault level the following results show the peak values and the average values of the voltage asymmetry for operation with three minutes headway and five minutes headway.

Table 1: Voltage Unbalance at the PCC of TSS1 and TSS2 for 3 Minutes Headway

\begin{tabular}{|c|c|c|c|c|}
\hline $\begin{array}{c}\text { Voltage } \\
\text { Unbalance }\end{array}$ & $\begin{array}{c}\text { Instantaneo } \\
\text { us }\end{array}$ & $\begin{array}{c}\text { 5 minutes } \\
\text { average } \\
\text { value }\end{array}$ & $\begin{array}{c}\text { 10 minutes } \\
\text { average value }\end{array}$ & $\begin{array}{c}\text { 15 minutes } \\
\text { average value }\end{array}$ \\
\hline TSS 1 & 0.69 & 0.40 & 0.38 & 0.38 \\
\hline TSS 2 & 2.48 & 1.71 & 1.70 & 1.67 \\
\hline
\end{tabular}

Table 2: Voltage Unbalance at the PCC of TSS1 and TSS2 for 5 Minutes Headway

\begin{tabular}{|c|c|c|c|c|}
\hline $\begin{array}{c}\text { Voltage } \\
\text { Unbalance }\end{array}$ & Instantaneous & $\begin{array}{c}\text { 5 minutes } \\
\text { average value }\end{array}$ & $\begin{array}{c}\text { 10 minutes } \\
\text { average value }\end{array}$ & $\begin{array}{c}\text { 15 minutes } \\
\text { average value }\end{array}$ \\
\hline TSS 1 & 0.39 & 0.24 & 0.24 & 0.23 \\
\hline TSS 2 & 1.52 & 1.02 & 1.02 & 1.00 \\
\hline
\end{tabular}

Considering that acc. to GB/T 15543-1995 the top 5\% of the values can be ignored and that peak operation with 3 minutes headway will be performed only at 35 min per day $(=2.43 \%)$ the results for 5 minutes operation can be used for the assessment. This means that $95 \%$ of all considered average unbalance values are within $1.3 \%$.

\section{Harmonics Results}

Due to the missing harmonic impedances, an estimation of harmonic voltages basing on the minimum short-circuits power of the power of the $220 \mathrm{kV}$ high voltage system has been carried out. The calculations are based on the results of network calculation with simulated train operation and the harmonic currents of the EMU. The calculations consider the worst-case operational scenarios in relation to harmonics. The main transformers of the traction supply substations are connected in $\mathrm{V}$ connection between the phase A-B respectively B-C.

At the point of common coupling to the high voltage network the requirements of the supply authorities concerning harmonic currents and harmonic voltage distortion have to be considered. 


\section{1) Harmonic Currents:}

An operation of fifteen EMUs for feeding section of TPSS1 has been considered generating maximum harmonic distortion in the high-voltage grid at the point of common coupling. Following figure shows the maximum harmonic current at the PCC of TSS1 $(220 \mathrm{kV}$ level), i.e. the theoretical worst case with all thirteen trains taking maximum power.

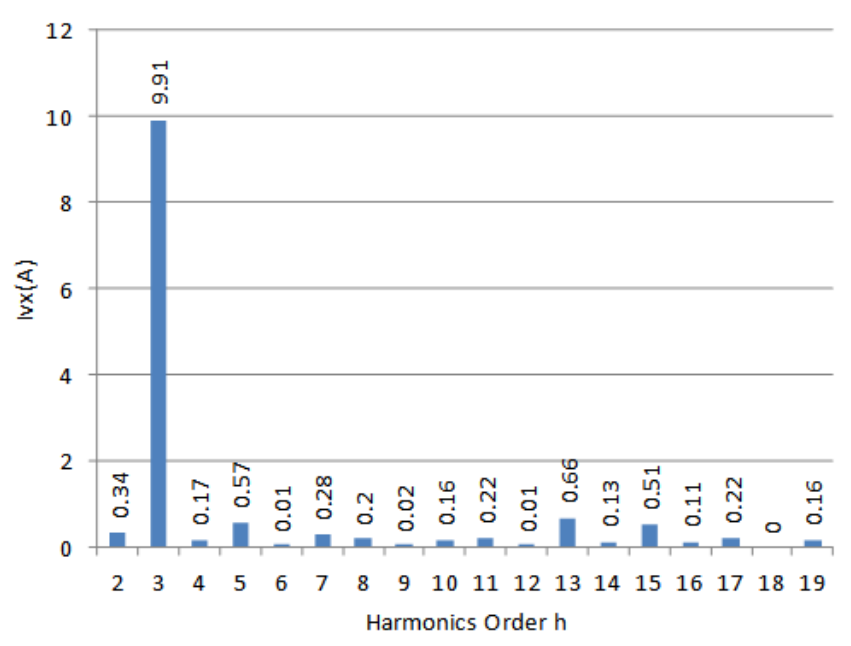

Figure 3: Maximum harmonic current at the PCC of TPSS2 with 15 trains

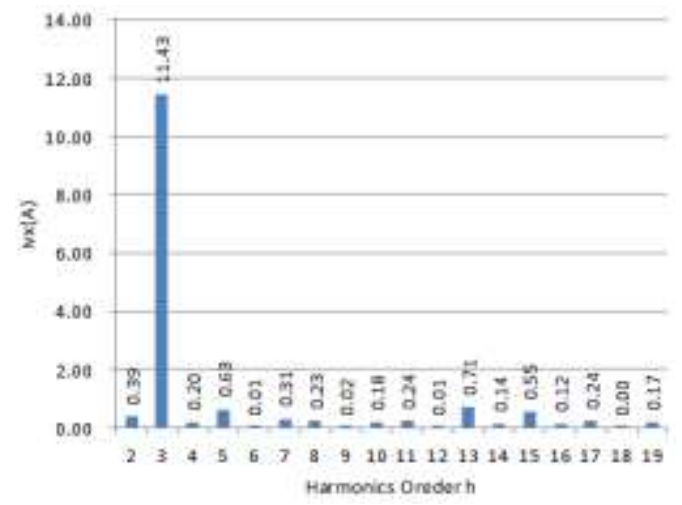

Figure 4. Maximum harmonic current at the PCC of TPSS1 with 13 train

An operation of fifteen EMUs for feeding section of TSS2 has been considered generating maximum harmonic distortion in the high-voltage grid at the point of common coupling. Following figure shows the maximum harmonic current at the PCC of TSS2 $(220 \mathrm{kV}$ level), i.e. the theoretical worst case with all fifteen trains taking maximum power.

The harmonic currents will be fed into the catenary system by each train and will be transferred into the high voltage grid via the substation transformer. Trains feed harmonic currents at different points with different phase angles and magnitudes into the catenary system. The phase angle of the harmonic currents differs for each train.

2) Harmonic Voltage Distortion :

The following pictures show the extreme operating mode, the harmonic distortion rate of the simulation results, which was compared with the IEC61000-3-6 standard, as shown in figure5 and figure 6: 


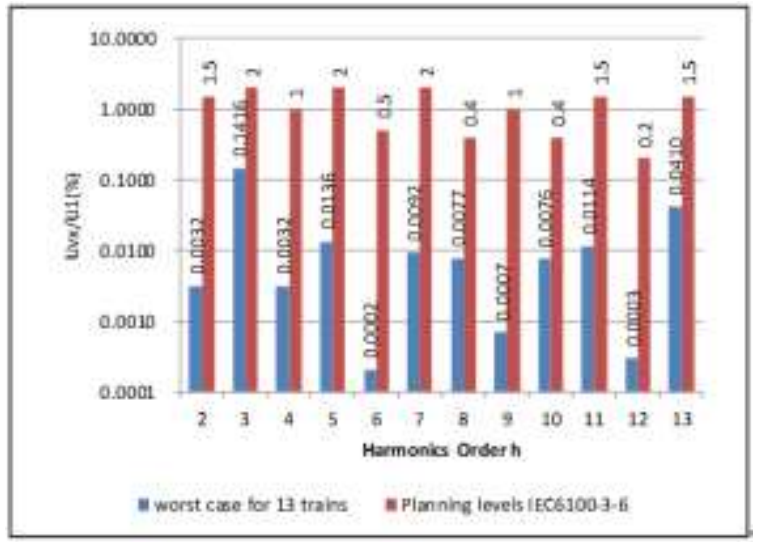

Figure 5: Harmonic voltage distortion at TPSS1, logarithmic scale

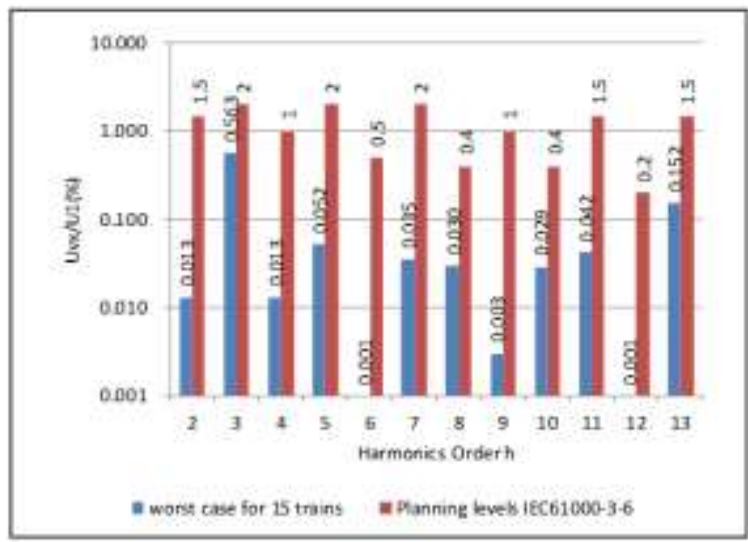

Figure 6: Harmonic voltage distortion at TPSS2, logarithmic scale

\section{3) Total harmoic voltage distortion}

Based on the results shown in above figures the total harmonic voltage distortion at the two PCCs is estimated. The THVD of TPSS 1 is $0.19 \%$ and the THVD of TPSS 2 is $0.58 \%$. And in IEC 61000-3-6 a planning level of 3\% is recommended.

The exact harmonic currents for real operation will differ from the calculated values depending on the schedule of trains and on the detailed design of the trains. Most likely lower values will turn out, due to the worst case assumption for the calculations with all trains in $100 \%$ traction mode. Figure 5 and 6 show that the calculated harmonic voltage are well below the planning levels recommended in IEC61000-3-6.

\section{Conclusions}

This paper presents a traction power supply system power quality evaluation method. Using this method, traction power supply system model is built in PSCAD / EMTDC simulation platform, and the harmonic and negative sequence power quality problems are simulated.

High-speed railway general use $220 \mathrm{kV}$ power supply which has large short circuit capacity and has smaller effect on power system. Electric locomotive of AC-DC-AC has smaller harmonic. Harmonic voltage meets related standards, but high harmonic may cause harmonic amplification even resonance phenomenon. So, further research combined with actual situation is needed. 
When the traction substation parameters and the traction load characteristics are known, the method provided in this paper can be used estimated or forecasted the level of harmonic and negative sequence on traction substation primary side.

\section{Acknowledgment}

The authors gratefully acknowledge Dr. Minwu Chen from Southwest Jiaotong University for his help and offer of measured current data on EMU. Project is supported by Major Technology Program of Railway Ministry (Z2006-407), National Key Technology R\&D program (No.2007BAA12B05) and Railway Department of P. R. China under project Number Z2005-047 and 2007J035

\section{References}

[1] Cao Jianyou, Traction Power Supply System for Electrified railway. China, Beijing: China Railway Publishing Company, 1983.

[2] Li Qunzhan, the Analysis and Synthesize Compensation Technique of Traction power supply system [M], Beijing: China Railway Publishing House, 2006.1.

[3] Li Qunzhan, He Jianmin, Traction Power Supply System Analysis. China, Chengdu: Southwest Jiaotong University, 2007.

[4] Hang Liu; Qunzhan Li; Fenghua Gao, " Traction Power System Model and Simulation for Estimation and Forecast of Traction Load," Power and Energy Engineering Conference, 2010. APPEEC 2010. Asia-Pacific, vol., no., pp. March 2010

[5] Moxue Li; Jinghan He; Le Yu; Bo, Z.Q.; Klimek, A., "Developments in digital simulation of traction transformer," Universities Power Engineering Conference, 2008. UPEC 2008. 43rd International, vol., no., pp.1-4, 1-4 Sept. 2008

[6] Yuen, K.H.; Pong, M.H.; Lo, W.C.; Ye, Z.M., "Modeling of electric railway vehicle for harmonic analysis of traction power-supply system using spline interpolation in frequency domain," Applied Power Electronics Conference and Exposition, 1999. APEC '99. Fourteenth Annual, vol.1, no., pp.458-463 vol.1, 14-18 Mar 1999

[7] Foiadelli, F.; Pinato, P.; Zaninelli, D., "Statistical model for harmonic propagation studies in electric traction supply systems," Harmonics and Quality of Power, 2004. 11th International Conference on, vol., no., pp. 753-758, 12-15 Sept. 2004

[8] Gao Lin; Xu Yonghai; Xiao Xiangnin; Liu Yingying; Jiang Peisi, "Analysis of adverse effects on the public power grid brought by traction power-supply system," Electric Power Conference, 2008. EPEC 2008. IEEE Canada, vol., no., pp.1-7, 6-7 Oct. 2008

[9] Gholizad, B.; Akhbari, M., "A new algorithm for simultaneously compensating harmonics and load unbalance in single phase traction systems," Industrial Technology, 2009. ICIT 2009. IEEE International Conference on , vol., no., pp.1-6, 10-13 Feb. 2009

[10] Dai Wenjin; Wu Songhui, "Real-Time Detecting Method of Negative Sequence Current in Traction System," Electronic Measurement and Instruments, 2007. ICEMI '07. 8th International Conference on , vol., no., pp.3-829-3-832, Aug. 16 2007-July 182007

[11] Li Qunzhan, Zhang Jinsi, He Weijun, Study of A New Power Supply System for Heavy Haul Electric Traction, Journal of the China Railway Society, 1988.12: pp. 23-30.

[12] Li Qunzhan, Symmetrical Compensations in the Traction Feeding System without Phase Exchange, Journal of the China Railway Society, 1991.10: pp. 23-30.

[13] He Jianmin, Li Qunzhan, Symmetrical Compensation Technology Used in Feeding System without Phase Exchange, Journal of the China Railway Society, 1998.12: pp. 47-51.

[14] Zeng Guohong, Siamak Farshad, Hao Rongtai, A novel traction power supply system based on 3/1 phase balanced power converter, Electric Drive for Locomotive, 1999.5. pp. 14-21.

[15] Wu Mingli, LI Qunzhan, Connection forms and compensator capacity determination of symmetrical compensation for cophase supply, Electric Drive For Locomotive, 2000.9. pp. 15-18. 
[16] Xie Shaofeng, LI Qun-zhan, Control strategy of symmetry compensation system for traction power supply system in phase, 2002.4: p109-113.

[17] Ouyang Fan, Zhou Youqing, Guo Ziyong, A Compensation Method for Current Balance Based on Balance Transformer, Transactions of China Electro Technical Society, 2007.5 pp. 53-p57.

[18] Wang guo, Ren enen, Tian Mingxing. A hybrid Active Compensation Method for Current Balance Based on Y, d11 connection traction transformer, PEITS 2008: pp. 582-586.

[19] Zhang Xiu-feng, Gao Shi-bing, A Novel Cophase Traction Power Supply System Based on Impedance Matching Balance Transformer and AT Power Supply Mode, Journal of the China Railway Society, 2006.8. pp. 32-37.

[20] Gao Fenghua, Gao Shibin, Liu Shuping, "A Novel Technique to Distinguish Between Transient and Permanent Faults Based on Signal Wavelet Singularity Detection," 2009 International Conference on Energy and Environment Technology (ICEET09), IEEE Press, Oct. 2009, in press.

[21] Zeng Guohong, Hao Rongtai, "Cophase traction supply system based on active power filter and impedance-matching balance transformer," Journal of The China Railway Society, 2003, 25(3), pp. 49-54.

[22] Zeng Guohong, Hao Rongtai, "Cophase Traction Supply System Based on Active Power Filter and Scott Transformer," Journal of Northern Jiaotong University, 2003, 27(4), pp. 84-90.

[23] Zeng Guohong, Siamak Farshad, Hao Rongtai, "A Novel Traction Power Supply System Based on 3/1 Phase Balanced Power Converter," Electrical Drive for Locomotives, vol. 3, May. 1999, pp. 14-17,21. 